\title{
Effectiveness and safety of elvitegravir/cobicistat/emtricitabine/tenofovir disoproxil fumarate single-tablet combination among HIV-infected patients in Turkey: results from a real world setting
}

\author{
Bilgul Mete ${ }^{1}$, Alper Gunduz², Hayat Kumbasar Karaosmanoglu³, Fatma Gumuser ${ }^{4}$, Sibel Bolukcu, \\ Dilek Sevgi Yildiz², Ozlem Altuntas Aydin³, Bilgenur Bilge ${ }^{6}$, Ilyas Dokmetas², Fehmi Tabak ${ }^{1}$
}

1. Istanbul University-Cerrahpasa, Cerrahpasa School of Medicine Department of Infectious Diseases and Clinical Microbiology

2.Sisli Hamidiye Etfal Research and Training Hospital Department of Infectious Diseases and Clinical Microbiology

3.Bakirkoy Dr Sadi Konuk Research and Training Hospital, Department of Infectious Diseases and Clinical Microbiology

4.Goztepe Medeniyet University, Medical School Department of Infectious Diseases and Clinical Microbiology 5.Bezm-i Alem University, Vakif Gureba Hospital, Department of Infectious Diseases and Clinical Microbiology 6.Istanbul University-Cerrahpasa, Cerrahpasa School of Medicine Department of Medical Genetics

All authors meet the ICMJE authorship criteria.

\begin{abstract}
Background: Efficacy of elvitegravir/cobicistat/emtricitabine/tenofovir disoproxil (E/C/F/TDF) in treatment-naïve and experienced patients with HIV infection was demonstrated in phase 3 trials. The primary objective of this study was to evaluate effectiveness and safety of $\mathrm{E} / \mathrm{C} / \mathrm{F} / \mathrm{TDF}$ in real world settings.

Methods: Retrospective, observational data collected by the Turkish ACTHIV-IST study group between May 2015 and December 2016 were analysed.

Results: A total of 387 patients were prescribed E/C/F/TDF; 210 patients with available data at 6th month were eligible; $91.5 \%$ were male, and mean age was 35.2 (SD: 10.8 ) years; $54.0 \%$ of males identified themselves as MSM. Sixty-three percent (133) of the study population were treatment-naïve patients, and 37\% (77) were treatment experienced. HIV RNA level was below 100 copies $/ \mathrm{mL}$ in $78.9 \%$ of treatment-naïve patients and $89.9 \%$ of treatment experienced patients at month 6 . Median increase in CD4 T lymphocyte count was 218 copies $/ \mathrm{mL}$ in treatment-naïve patients and remained stable or increased in treatment experienced patients. Adverse events were observed in $15 \%$ of the patients, and the regimen was discontinued in only six patients.

Conclusion: Real world data on the effectiveness and safety of $\mathrm{E} / \mathrm{C} / \mathrm{F} / \mathrm{TDF}$ is comparable with the phase 3 trial results Adverse events are uncommon and manageable.

Keywords: Elvitegravir/cobicistat/emtricitabine/tenofovir disoproxil fumarate, HIV, effectiveness, safety

DOI: https://dx.doi.org/10.4314/abs.v21i4.13

Cite as: Mete B, Gunduz, A, Karaosmanoglu HK, Gumuser F, Bolukcu S, YildizDS, et al. Effectiveness and safety of elvitegravir/cobicistat/ emtricitabine/ tenofovir disoproxil fumarate single-tablet combination among HIV-infected patients in Turkey: results from a real world setting. Afri Health Sci. 2021;21(4):1593-602. bttps:// dx.doi.org/10.4314/abs.v21i4.13
\end{abstract}

\section{Corresponding author:}

Bilgul Mete, Assoc. Prof.

Istanbul University Cerrahpasa School of Medicine,

Department of Infectious Diseases and Clinical

Microbiology, Cerrahpasa/Fatih;Istanbul,Turkey

Telephone number: +90 5326909489

E-mail: bigimete@yahoo.com

\section{Introduction}

The World Health Organisation (WHO) estimates that 36.7 million people were living with human immunodeficiency virus (HIV) in 2016, and 1.8 million of them were newly infected in that year. Moreover, HIV infection caused approximately 1 million death globally ${ }^{1}$. In 2016, 69.5\% othe people living with HIV (PLWH) were diagnosed, of whom $76.5 \%$ were on antiretroviral ther-

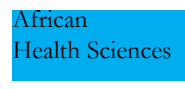

C) 2021 Mete B et al. Licensee African Health Sciences. This is an Open Access article distributed under the terms of the Creative commons Attribution License (https://creativecommons.org/licenses/BY/4.0), which permits unrestricted use, distribution, and reproduction in any medium, provided the original work is properly cited. 
apy (ART). Of those on ART, $82.1 \%$ were virologically suppressed ${ }^{1}$.

The Turkish Public Health Authority reported that a total of 16644 people had been diagnosed with HIV infection from 1985 through June 2017, and 1537 people had been diagnosed with acquired immune deficiency syndrome (AIDS) during the same time period ${ }^{2}$. Although the exact number of alive PLWH in Turkey is not known, a recent study revealed that there may be 23192 adults living with HIV infection in Turkey, of whom half $(48.9 \%)$ have been diagnosed ${ }^{3}$.

Since life-long treatment with an ART regimen consisting of at least three drugs is recommended, multi-tablet regimens (MTRs) may compromise adherence to treatment and result in decrease in quality of life and treatment success ${ }^{4}$. Single-tablet regimens (STRs) combing multiple agents are available and have been associated with clinically significant advantages over MTRs ${ }^{5}$.

The first boosted integrase strand transfer inhibitor (INSTI)-based combination available was a fixed combination of elvitegravir (150 mg), cobicistat (150 mg), emtricitabine $(200 \mathrm{mg})$ and tenofovir disoproxil fumarate $(245 \mathrm{mg})(\mathrm{E} / \mathrm{C} / \mathrm{F} / \mathrm{TDF} \text {, Stribild } \AA)^{6}$.

Efficacy of $\mathrm{E} / \mathrm{C} / \mathrm{F} / \mathrm{TDF}$ in ART naïve and treatment experienced patients compared to other combinations was shown in phase trials. The results of the phase 3 trials revealed that $\mathrm{E} / \mathrm{C} / \mathrm{F} / \mathrm{TDF}$ was effective in more than $80 \%$ of treatment-naïve and $78-87 \%$ of treatment experienced patients ${ }^{7-11}$.

$\mathrm{E} / \mathrm{C} / \mathrm{F} / \mathrm{TDF}$ has been well tolerated by both treatment-naïve and treatment-experienced patients. Most adverse events reported in these studies were mild or moderate ${ }^{7-17}$. The most commonly reported adverse events (reported for $\geq 1 / 10$ ) are abnormal dreams, asthenia, diarrhea, elevated creatine kinase, headache, hypophosphatemia, insomnia, nausea, rash and vomiting. Patients on E/C/F/TDF should be followed for loss of bone mineral density and renal toxicity, including proximal tubulopathy. $\mathrm{E} / \mathrm{C} / \mathrm{F} / \mathrm{TDF}$ is not recommended in patients with creatinine clearance $<70 \mathrm{~mL} /$ minute or previous renal impairment history due to $\mathrm{TDF}^{6}$.

$\mathrm{E} / \mathrm{C} / \mathrm{F} / \mathrm{TDF}$ was approved in 2013 and has been widely used in Turkey. Real world data on the effectiveness and safety data of $\mathrm{E} / \mathrm{C} / \mathrm{F} / \mathrm{TDF}$ has not been published in a detailed manner so far. We present real world data on the effectiveness and safety of E/C/F/TDF using one of the largest HIV databases in Turkey.

\section{Material and methods}

ACTHIV-IST (ACTion against HIV in ISTanbul) is a study group founded in 2012. The aim of this local study group was to establish a database collecting data on PLWH from 5 major centres in Istanbul involving approximately $20 \%$ of HIV-infected patients in Turkey. The list of participating centres is included in the acknowledgement section.

Due to the observational nature of the study, data collection procedures of ACTHIV-IST database do not require interventions in addition to the routine practice of the centres; however, the centres are expected to record all available data in the database. Collected data include demographics, medical characteristics, HIV infection and treatment history, including adherence, HIV RNA levels, CD4 T-lymphocyte results, and adverse events. The primary objective of this analysis was to evaluate effectiveness and safety of $\mathrm{E} / \mathrm{C} / \mathrm{F} / \mathrm{TDF}$ in real world settings in $\mathrm{HIV}$-infected patients. Data collected from all treatment-naïve and -experienced patients on $\mathrm{E} / \mathrm{C} / \mathrm{F} /$ TDF who provided written consent and had at least 6 months of follow-up were included. There were no exclusion criteria. The data analysed in the manuscript were collected between May 2015 and December 2016. Each centre used its local laboratory, and each laboratory followed its own standard operating procedures. HIV RNA measurement technique varied across laboratories, and with one hospital using a detection threshold of 100 copies $/ \mathrm{mL}$. Therefore, an undetectable HIV RNA viral load was defined as $<100$ copies $/ \mathrm{mL}$ in this study.

Adverse events were classified and reported by using the medical dictionary for regulatory activities (MedDRA).

No formal sample size calculation was made since all eligible patients were included using a consecutive sampling technique. Participating centres were expected to show maximum effort to minimize loss to follow-up. No replacement or adjustment analysis for missing data was planned for the patients lost to follow-up. Due to the nature of the study, descriptive statistics (count and percentage for categorical data; mean, standard deviation [SD]- or median, iter-quartile range [IQR]- for numeric data) were used to summarize the data. Analyses were performed intent-to-treat population. Some analyses were repeated for all treatment-experienced patients, treatment-experienced patients with a history of prior treatment failure patients and treatment-naïve patients with baseline HIV RNA level $\geq 100,000$ copies $/ \mathrm{mL}$. 


\section{Results}

\section{Descriptive and medical characteristics}

ACTHIV-IST database included data on 387 patients on E/C/F/TDF at the end of 2016 with 2736 patient-month follow-up data. Of those, $91.0 \%$ were male, mean age was 35.0 (SD: 10.7 ) years, and $53.4 \%$ of males described themselves as men who have sex with men (MSM). Of the 387 patients, 225 (58.1\%) were ART naïve and $162(41.9 \%)$ were antiretroviral treatment experienced (Table 1$)$.
Most of the treatment-naïve patients (95.6\%) were male, with mean age 33.7 (SD: 10.3 ) years; $54.0 \%$ of males described themselves as MSM. HBsAg (3.6\%) and anti-HCV (1.3\%) positivity were uncommon, and one-third of patients $(31.1 \%)$ had at least one comorbidity. Treatment-naïve patients were diagnosed with HIV infection for a median duration of 16.0 months (IQR: 12.0-21.0) and were on E/C/F/TDF for a median of 11.0 months (IQR: 8.0-14.0). E/C/F/TDF was started within 3 months of HIV diagnosis in $55.1 \%$ of treatment-naïve patients (Table 1).

Table 1. Demographics and medical characteristics of patients in the ACTHIV-IST database

\begin{tabular}{|c|c|c|c|}
\hline & Total $(n=387)$ & $\begin{array}{l}\text { ART experienced } \\
(\mathrm{n}=162)\end{array}$ & $\begin{array}{l}\text { ART naive } \\
(\mathrm{n}=225)\end{array}$ \\
\hline \multicolumn{4}{|l|}{ Demographics } \\
\hline Gender, male; n (\%) & $352(91.0 \%)$ & $137(84.6 \%)$ & $215(95.6 \%)$ \\
\hline Age, years; mean $(\mathrm{SD})$ & $35.0(10.7)$ & $36.8(11.0)$ & $33.7(10.3)$ \\
\hline Sexual orientation, MSM; $\mathrm{n}(\%)^{*}$ & $188(53.4 \%)$ & $114(53.0 \%)$ & $74(54.0 \%)$ \\
\hline \multicolumn{4}{|l|}{ Medical characteristics } \\
\hline Positive HBsAg; n (\%) & $17(4.4 \%)$ & $9(5.6 \%)$ & $8(3.6 \%)$ \\
\hline Positive anti-HCV; n (\%) & $4(1.0 \%)$ & $1(0.6 \%)$ & $3(1.3 \%)$ \\
\hline \multicolumn{4}{|l|}{ Concomitant disease; $\mathrm{n}(\%)^{* *}$} \\
\hline Any & $126(32.6 \%)$ & $56(34.6 \%)$ & $70(31.1 \%)$ \\
\hline HPV infection & $26(6.7 \%)$ & $8(4.9 \%)$ & $18(8 \%)$ \\
\hline Syphilis & $22(5.7 \%)$ & $9(5.6 \%)$ & $13(5.8 \%)$ \\
\hline Diabetes mellitus & $14(3.6 \%)$ & $4(2.5 \%)$ & $10(4.4 \%)$ \\
\hline Hypertension & $14(3.6 \%)$ & $6(3.7 \%)$ & $8(3.6 \%)$ \\
\hline \multicolumn{4}{|l|}{ HIV infection related parameters } \\
\hline $\begin{array}{l}\text { HIV infection duration, month; } \\
\text { median (IQR) }\end{array}$ & $\begin{array}{l}22.0(15.0- \\
39.0)\end{array}$ & $39.5(29.0-63.0)$ & $16.0(12.0-21.0)$ \\
\hline $\begin{array}{l}\text { Total antiretroviral treatment } \\
\text { duration, month; median (IQR) }\end{array}$ & $\begin{array}{ll}15.0 & (10.0- \\
28.0) & \\
\end{array}$ & $31.5(23.0-54.0)$ & $11.0(8.0-14.0)$ \\
\hline $\begin{array}{l}\mathrm{E} / \mathrm{C} / \mathrm{F} / \mathrm{TDF} \text { treatment } \\
\text { month; median (IQR) }\end{array}$ & $12.0(8.0-14.0)$ & $12.0(8.0-15.0)$ & $11.0(8.0-14.0)$ \\
\hline $\begin{array}{l}\text { Patient received antiretroviral } \\
\text { treatment within } \leq 3 \text { months after HIV } \\
\text { infection diagnosis; } \mathrm{n}(\%)\end{array}$ & $218(56.3 \%)$ & $94(58.0 \%)$ & $124(55.1 \%)$ \\
\hline
\end{tabular}


Of the 162 treatment-experienced patients, $84.6 \%$ were male and mean age was 36.8 (SD:11.0) years; $53.0 \%$ of males described themselves as MSM. HBsAg (5.6\%) and anti-HCV $(0.6 \%)$ positivity were uncommon, and one-third of patients $(32.6 \%)$ had at least one comorbidity. Treatment-experienced patients were diagnosed with HIV infection for a median duration of 39.5 months (IQR:29.0-63.0), had been on ART for a median of 31.5 months (IQR:23.0-54.0), and on E/C/F/ TDF for a median of 12.0 months (IOR:8.0-15.0). ART was started within 3 months of HIV diagnosis in $58.0 \%$ of treatment-experienced patients. The most commonly used previous NRTI backbone was F/TDF (96.3\%); the three most commonly used regimens were F/TDF + lopinavir/ritonavir (46.9\%), F/TDF + efavirenz $(43.2 \%)$, and $\mathrm{F} / \mathrm{TDF}+$ darunavir + ritonavir (4.3\%). Of the treatment-experienced patients; $24.1 \%$ (39/162) were switched to $\mathrm{E} / \mathrm{C} / \mathrm{F} / \mathrm{TDF}$ due to treatment failure, and $75.9 \%(123 / 162)$ changed treatment to simplify the treatment (Table 1).

To be able to determine the real world safety and effectiveness of $\mathrm{E} / \mathrm{C} / \mathrm{F} / \mathrm{TDF}$, only the patients with available data at 6 months were evaluated in this study. A total of 210 patients were eligible, of whom $91.5 \%$ were male and mean age was 35.2 years (SD 10.8), and 54.0\% of males identified themselves as MSM. Sixty-three percent (133) of the study population were treatment-naïve patients, and 37\% (77) were treatment experienced

\section{Treatment-naïve patients \\ Virologic efficacy}

Median baseline HIV-RNA level in treatment-naive patients was 112,228 copies/mL (IQR: 32,900-311,580). Six-month HIV RNA levels were available in 95\% (127), and 38\% (51) patients had available HIV RNA results at 12 months. HIV RNA level was below 100 copies/ $\mathrm{mL}$ in $78.9 \%$ of treatment-naive patients at month 6 (Figure 1). The patients were sub-grouped according to baseline HIV-RNA level as group I: < 100,000 copies/ $\mathrm{mL}(47 \%)$, group II: 100,000 to $<1,000,000$ copies/ $\mathrm{mL}(40 \%)$, and group 3: $\geq 1,000,000$ copies $/ \mathrm{mL}(13 \%)$. Median HIV-RNA level in all treatment-naïve patients decreased to 0 copies/mL (IQR: 0-93) at month 6. Median HIV-RNA level was 60 (IQR: 0-132) and 20 (IQR: $0-117)$ copies/mL in group III and group II, respectively. In 51 patients having results of HIV RNA level at month 12, median HIV RNA level was $<100$ copies / $\mathrm{mL}$ (Figure 2,3).

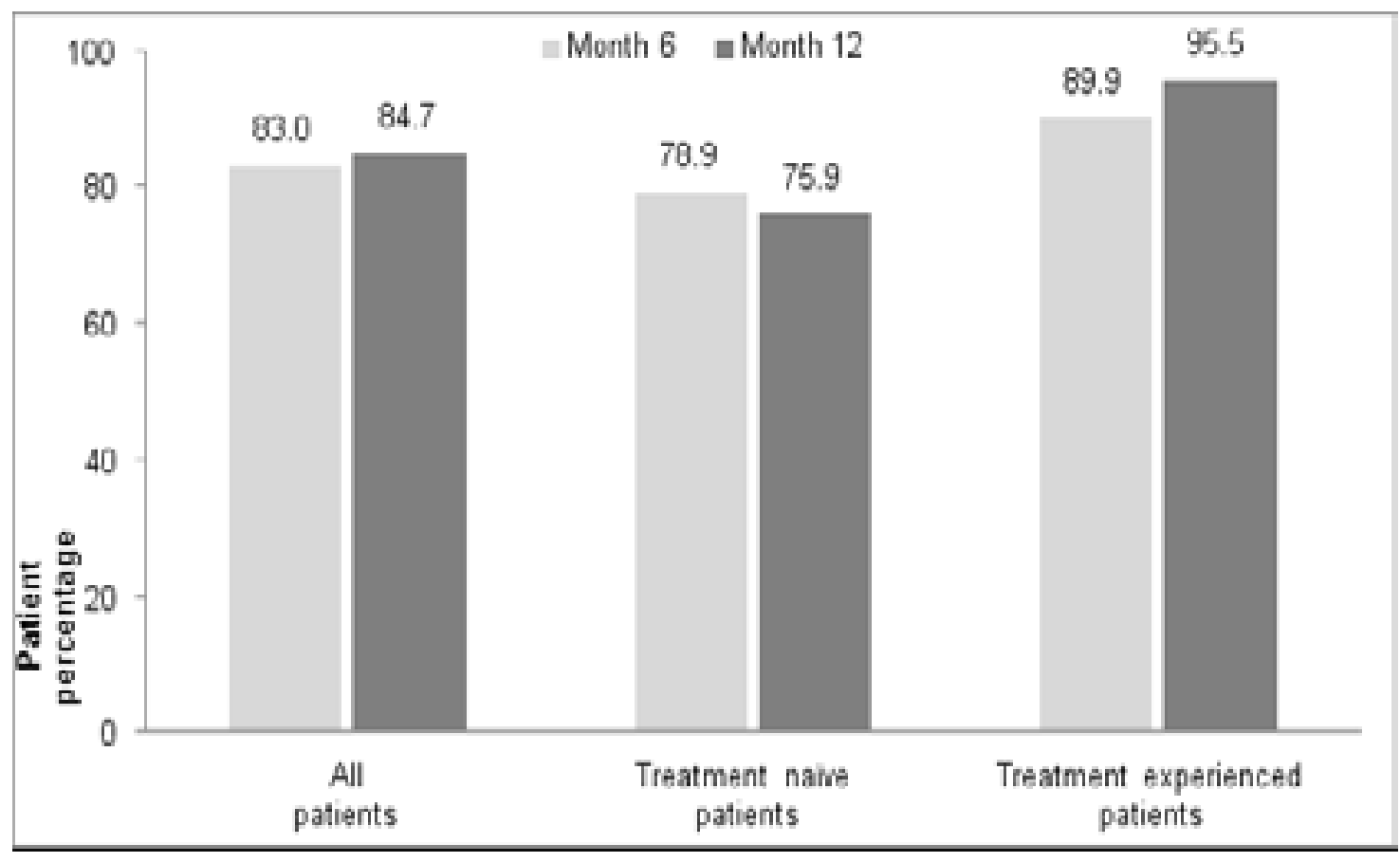

Figure 1. Percentage of patients with HIV RNA $<100$ copies/ml at month 6 and month 12 


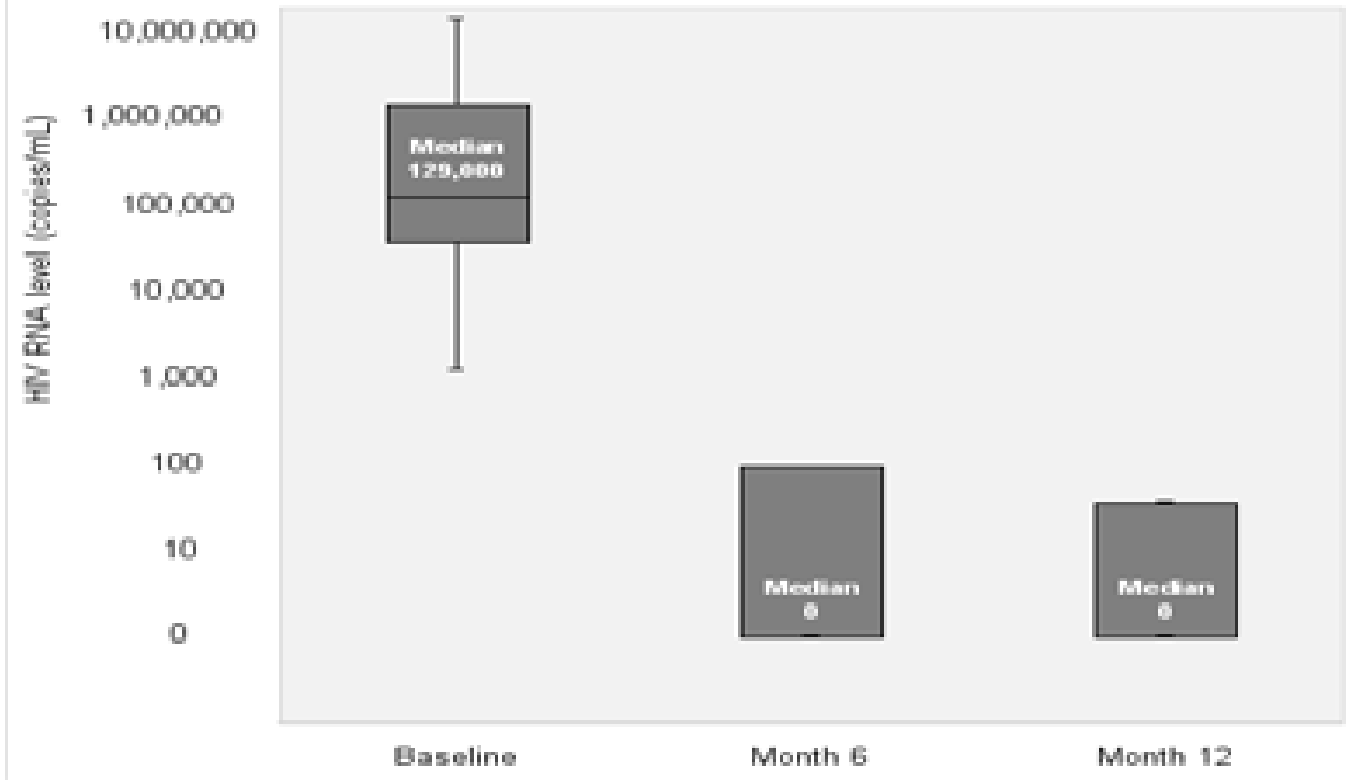

Figure 2. HIV RNA level (copies/mL) over time in treatment naïve patients

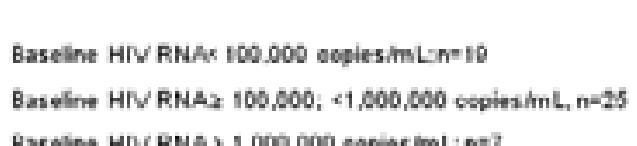
Baseline HIV RNA $>1.000 .000$ eopiesimL: $n=7$

Baseline HV RNA 100.000 eopies/mL: No6 (47\%)

Baselim HN RNA $100.000 ; \times 1,000,000$ sopies $/ m L, n-51$ (40 z)

Baseline HIV RNA> 1.000 .000 oopies/mL:n=16 (538)

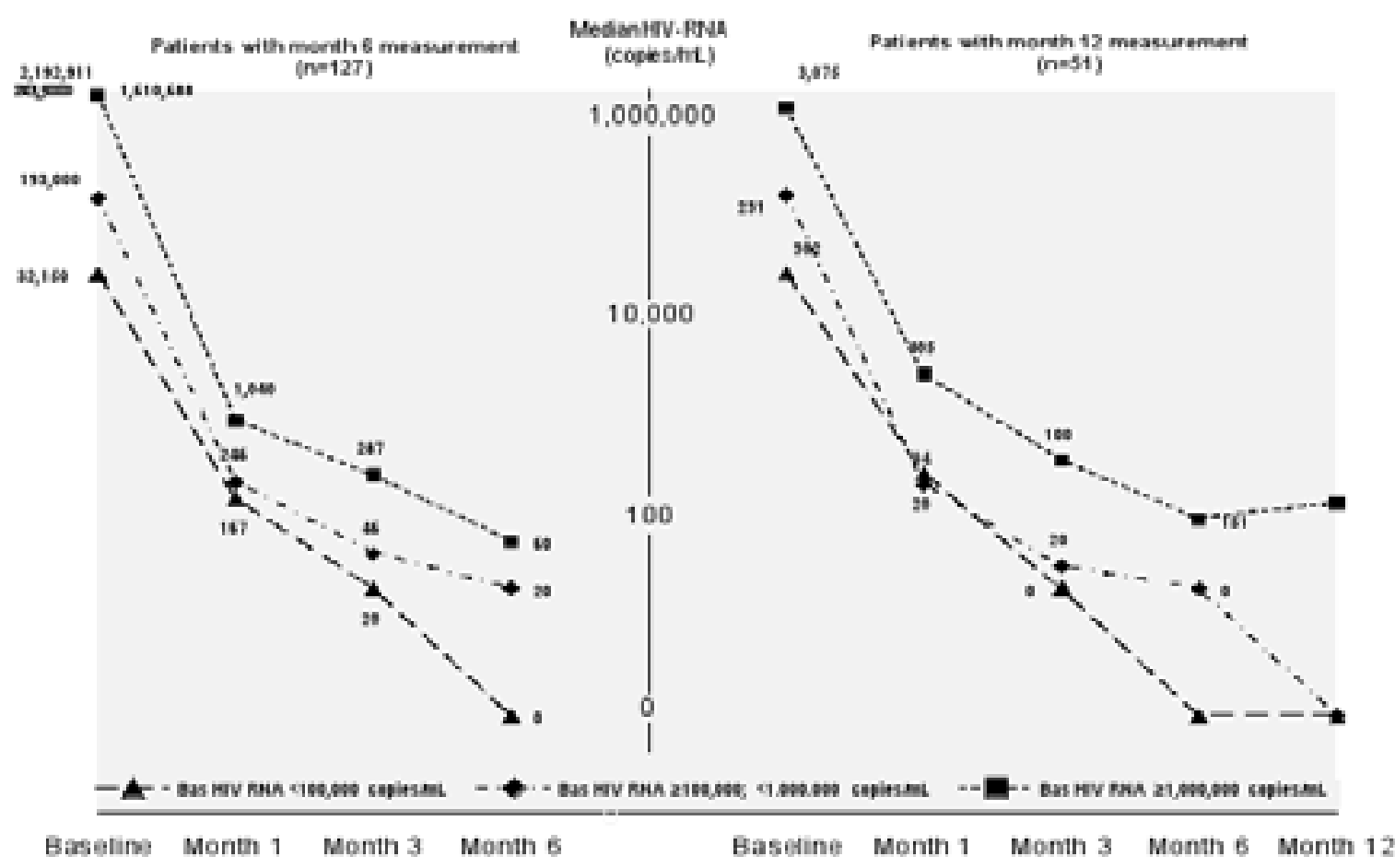

Figure 3. HIV RNA level (median, copies $/ \mathrm{mL}$ ) of patients with $6^{\text {th }}$ month and 12 th month measurements regarding baseline HIV RNA level subgroups in treatment naïve patients 


\section{Immunologic recovery}

Six-month CD4 T lymphocyte results were available in all of the patients (133) and in in 37\% (49) at 12 months. Median CD4 T lymphocyte level in all treatment-naïve patients was 384 (IQR: 281-516) copies/mL at baseline and increased to 602 (IQR: 444-745) copies/mL at month 6 (median increase 218 copies $/ \mathrm{mL}$ ).

Patients were sub-grouped according to CD4 T lym- phocyte level as group I: $<350$ copies $/ \mathrm{mL}(\mathrm{n}=50)$, group II: 350 to $<500$ copies $/ \mathrm{mL}$ ( $\mathrm{n}=51)$, and group 3: $\geq 500$ copies $/ \mathrm{mL}$ ( $\mathrm{n}=32$ ).

Median CD4 T lymphocyte level was 247, 405 and 601 copies/mL at baseline and increased to 432, 631 and 829 copies $/ \mathrm{mL}$ at month 6 in group I, II and III, respectively. Median CD4 T lymphocyte level continued to increase to 539 copies $/ \mathrm{mL}$ in group I and remained stable in groups II and III at month 12 (Figure 4).

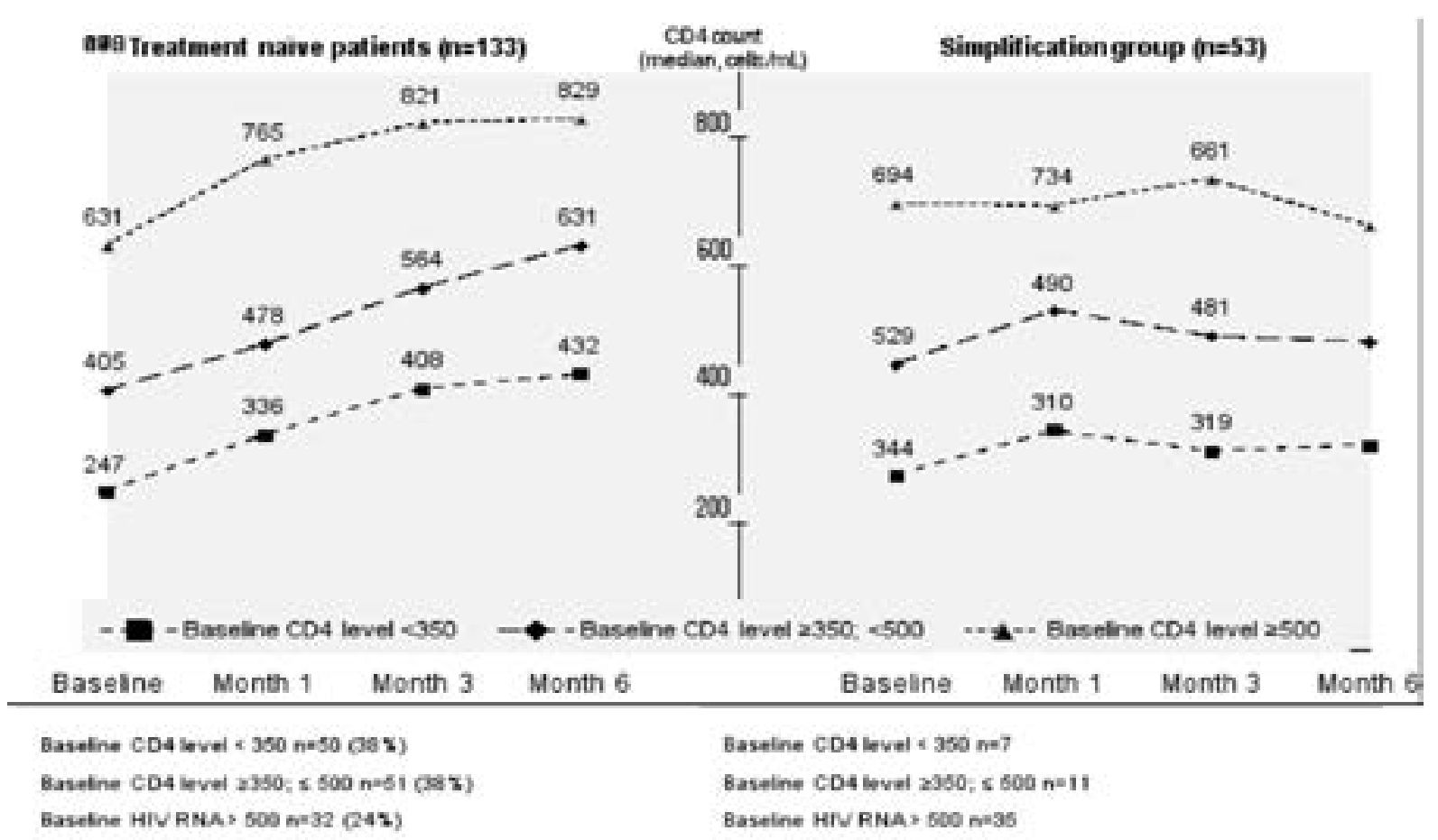

Figure 4. CD4+T lymphocyte count (median, cells/mL) of patents with 6th month measurements recarding baseline $\mathrm{CD} 4+\mathrm{T}$ lymptocyle level subgroups in treatrment naive patients $(\mathrm{n}=133)$ and simplification group $(n=53)$

\section{Treatment experienced patients Virologic efficacy}

Median HIV-RNA level of all treatment experienced patients $(\mathrm{n}=77)$ was available at baseline and at 6 th month. The patients were switched to $\mathrm{E} / \mathrm{C} / \mathrm{F} / \mathrm{TDF}$ due to simplification in 60 patients and because of virologic failure in 17. Median HIV-RNA level of all treatment experienced patients was 20 (IQR: 0-72) and 0 (IQR:
0 -20) copies/mL before E/C/F/TDF and at month 6, respectively, whereas HIV RNA level was below 100 copies $/ \mathrm{mL}$ in 77.9 and $89.9 \%$ of all treatment experienced patients at before $\mathrm{E} / \mathrm{C} / \mathrm{F} / \mathrm{TDF}$ and month 6 , respectively (Figure 1). Median HIV RNA level was 10 (IQR: $0-20)$ and 0 (IQR: 0-20) copies/mL in the simplification group and 822 (IQR: 461-64,700) and 20 (IQR: $0-58)$ copies $/ \mathrm{mL}$ in the virologic failure group before $\mathrm{E} / \mathrm{C} / \mathrm{F} / \mathrm{TDF}$ and at month 6, respectively (Figure 5). 


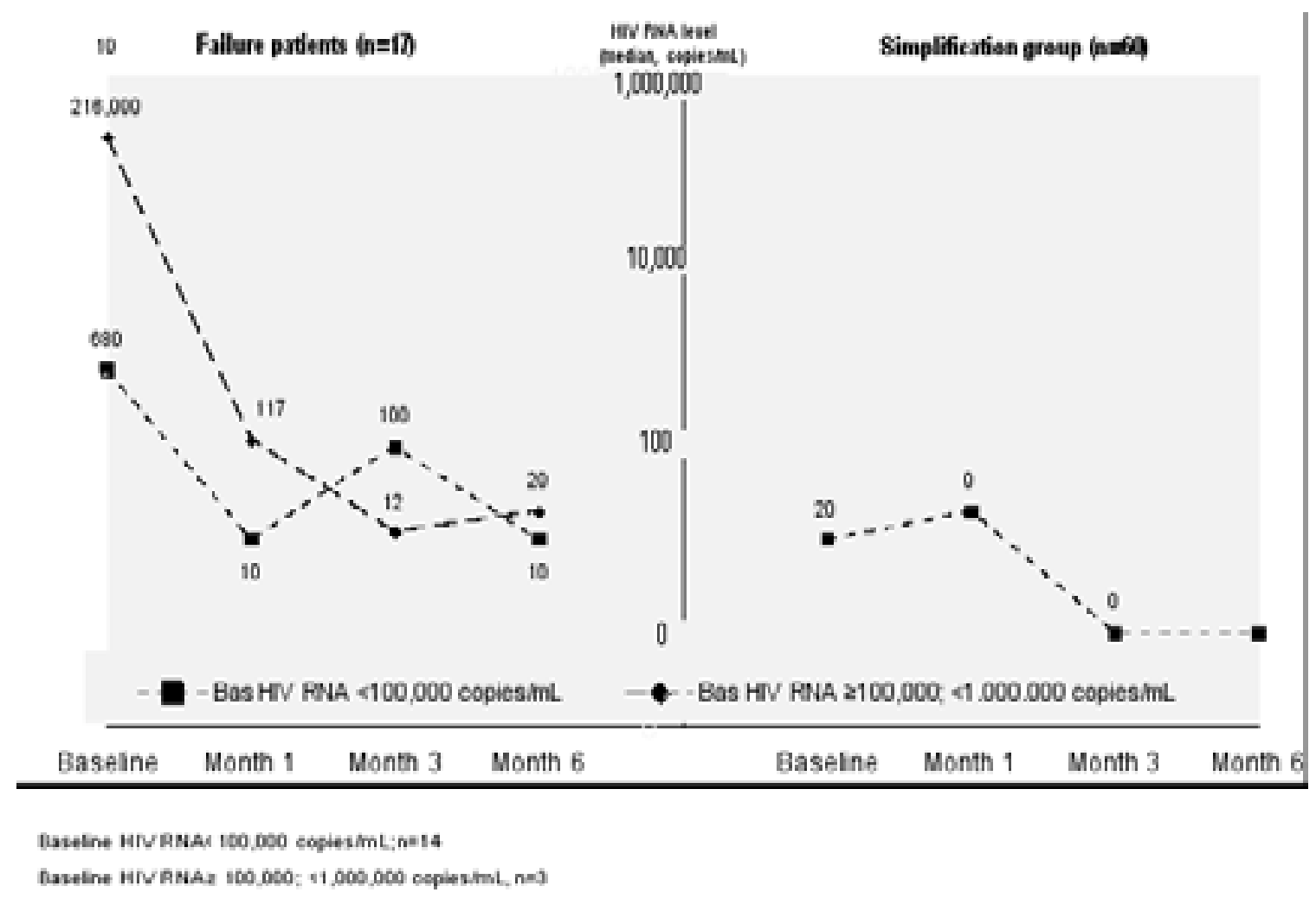

Figure 5. HIV RNA level (median, copies $/ \mathrm{mL}$ ) of patients with 6th month measurements regarding baseline HIV RNA level subgroups in treatment experienced (virological failure, $n=17$ ) and treatment experienced (simplification, $n=60$ ) patients

\section{Immunological recovery}

Median CD4 $\mathrm{T}$ lymphocyte level in treatment experienced patients before $\mathrm{E} / \mathrm{C} / \mathrm{F} / \mathrm{TDF}$ and at month 6 was 611 (IQR:458-748) and 598 (IQR: 454-824) copies/mL, respectively. Since the number of available results was too small, 12-month data were not evaluated.

Due to the greater number of the patients, the increase in CD4 $\mathrm{T}$ lymphocyte count was evaluated primarily in the simplification group. The patients were subgrouped according to CD4 $\mathrm{T}$ lymphocyte level as group I: $<350$ copies $/ \mathrm{mL}$ ( $\mathrm{n}=7$ ), group II: 350 to $<500$ copies $/ \mathrm{mL}(\mathrm{n}=11)$, and group $3: \geq 500$ copies $/ \mathrm{mL}(\mathrm{n}=35)$ (Figure 4).

Median CD4 T lymphocyte level was 272, 446 and 696 copies/mL at baseline and increased to 319, 481 and
661 copies $/ \mathrm{mL}$ at month 6 in group I, II and III respectively.

Seventeen patients were included in virologic failure group. Median CD4 T lymphocyte levels were 143, 451 and 652 copies $/ \mathrm{mL}$ at baseline and increased to 234, 560 and 839 copies/mL at month 6 in group I, II and III, respectively.

\section{Adverse events}

Adverse events were analysed in 387 patients having withat least 6 months of follow-up. During E/C/F/ TDF treatment, $14.9 \%$ (58) patients experienced adverse events. The adverse events (reported for $>1.0 \%$ of patients) were nausea $(8,2.1 \%)$, diarrhea $(7,1.8 \%)$, pruritus $(6,1.6 \%)$, asthenia $(5,1.3 \%)$, headache $(5$, $1.3 \%)$, dizziness $(4,1.0 \%)$ and dyspepsia $(4,1.0 \%)$ (Table 2). 
Table 2. Adverse events

\begin{tabular}{ll}
\hline Adverse event & n (\% in 387) \\
\hline Nausea & $8(2.1 \%)$ \\
\hline Diarrhea & $7(1.8 \%)$ \\
\hline Pruritus & $6(1.6 \%)$ \\
\hline Asthenia & $5(1.3 \%)$ \\
\hline Headache & $5(1.3 \%)$ \\
\hline Dizziness & $4(1.0 \%)$ \\
\hline Dyspepsia & $4(1.0 \%)$ \\
\hline Flatulence & $3(0.8 \%)$ \\
\hline Hyperhidrosis & $3(0.8 \%)$ \\
\hline Somnolence & $3(0.8 \%)$ \\
\hline Abdominal pain & $2(0.5 \%)$ \\
\hline Alopecia & $2(0.5 \%)$ \\
\hline Death & $2(0.5 \%)$ \\
\hline Rash & $2(0.5 \%)$ \\
\hline Weight increased & $2(0.5 \%)$ \\
\hline Total & $\mathbf{5 8 ( 1 4 . 9 \% )}$ \\
\hline
\end{tabular}

Adverse events with incidence $\geq \% 0.5$ were listed in the table

Two patients $(0.5 \%)$ died during treatment; neither death was attributed to E/C/F/TDF. Of 387 patients, six $(1.6 \%)$ drug discontinuations were reported: due to death 2 , drug-drug interaction ${ }^{1}$, elevated creatinine ${ }^{1}$, elevated liver enzyme ${ }^{1}$, and physician decision ${ }^{1}$.

\section{Discussion}

INSTIs prevent or inhibit the binding of the preintegration complex to host cell DNA. INSTI-based regimens result in a rapid early-phase decay of plasma HIV-RNA. All currently available INSTIs are included now among the recommended regimens, and once-daily regimens are recommended for both treatment-naïve patients beginning ART and experienced patients receiving complex or poorly tolerated regimens and to use fixed-dose combinations (FDCs) and STRs when possible to decrease pill burden ${ }^{13}$.

E/C/F/TDF was approved by the U.S. Food and Drug Administration (FDA) in August 2012 in a once-a-day STR to treat ART-naïve patients or ART-experienced patients with no resistance to its components ${ }^{14}$.

Except for phase 3 studies and case reports, there is only one study evaluating the effectiveness and safety of $\mathrm{E} / \mathrm{C} / \mathrm{F} / \mathrm{TDF}$ in the English literature so $\mathrm{far}^{15}$. This is the second study reporting real world data of the effectiveness of $\mathrm{E} / \mathrm{C} / \mathrm{F} / \mathrm{TDF}$ in PLWH.

The results of the phase 3 trials revealed that $\mathrm{E} / \mathrm{C} / \mathrm{F} /$ TDF was effective in more than $80 \%$ of treatment-naïve and $78-87 \%$ of treatment experienced patients ${ }^{7-11}$.
In a phase 2 study comparing $\mathrm{E} / \mathrm{C} / \mathrm{F} / \mathrm{TDF}$ to efavirenz (EFV)/F/ TDF for initial therapy, $90 \%$ of patients using $\mathrm{E} / \mathrm{C} / \mathrm{F} / \mathrm{TDF}$ had HIV-1 RNA $<50$ copies $/ \mathrm{mL}$ at week 24 and 48, and a median increase of CD4 T-lymphocyte of 205 copies/mL was observed at the end of 48 weeks $^{12}$.

A phase 3 study comparing E/C/F/TDF to EFV/ FTDF revealed that $86.7 \%$ of treatment-naive patients using E/C/F/TDF had HIV RNA $<50$ copies $/ \mathrm{mL}$ at week 48 , and a median increase of CD4 T-lymphocyte of 239 copies/mL was observed after 48 weeks of treatment ${ }^{8}$. The long-term extension of this study revealed that viral suppression persisted; $84.2 \%$ and $80.2 \%$ of the patients had HIV-1 RNA $<50$ copies/ $\mathrm{mL}$ at week 96 and 144 , respectively ${ }^{7,8}$.

In a phase 3 (study 103, compared to atazanavir + ritonavir + F/TDF); E/C/F/TDF $89.5 \%$ of participants were suppressed at week 48 , and $83.3 \%$ and $77.6 \%$ of patients maintained suppression at weeks 96 and 144, respectively ${ }^{16-18}$. A median increase of CD4 T-lymphocyte of 207 copies $/ \mathrm{mL}$ at 48 weeks was reported ${ }^{16}$.

In the present study HIV RNA suppression to below 100 copies $/ \mathrm{mL}$ was observed in $78.9 \%$ of the treatment-naïve patients at 24 weeks. When compared to the phase $2 / 3$ studies, rates of virological suppression similar, but it should be emphasized that HIV RNA level was $\geq 1,00,000$ copies $/ \mathrm{ml}$ in $13 \%$ and $\geq 100.000$ copies $/ \mathrm{ml}$ in $40 \%$ in our study. Squillace and colleagues found that viral load was undetectable in $77 \%$ of their 
naive patients $(n=78)$ at 24 weeks, similar to our results $^{15}$.

Median 6-month increase in CD4 T lymphocyte count was 218 copies $/ \mathrm{mL}$ in our study, which is similar to phase $2 / 3$ studies results demonstrating median increase of 205 to 239 copies $/ \mathrm{mL}$ at 12 months.

Eighteen patients had HIV RNA $>100$ copies/mL at 24 weeks. When these patients were evaluated separately, 55\% had baseline HIV RNA > 100,000 copies/ml, and $75 \%$ of the remaining patients were nonadherent to ART.

Adverse events, treatment failure, greater pill burden, and more frequent dosing have been associated with early ART discontinuation or modification ${ }^{14}$. The use of simpler and better tolerated regimens can improve outcomes. The efficacy of $\mathrm{E} / \mathrm{C} / \mathrm{F} / \mathrm{TDF}$ in simplification strategy was evaluated in several trials. In the STRATEGY-PI study a phase $3 \mathrm{~b}$ study switching from a ritonavir-boosted protease inhibitor plus $\mathrm{F} / \mathrm{TDF}, 93.8 \%$ and $86.9 \%$ of patients had HIV-1 RNA $<50$ copies $/ \mathrm{mL}$ at week 48 and 96 by switching to $\mathrm{E} / \mathrm{C} / \mathrm{F} / \mathrm{TDF}^{14,16}$. In the STRATEGY-NNRTI study, a phase 3b study switching from a non-nucleoside reverse transcriptase inhibitor (NNRTI) plus F/TDF, $93.4 \%$ and $86.6 \%$ of the patients switching to E/C/F/TDF had HIV-1 RNA $<50$ copies $/ \mathrm{mL}$ at week 48 and 96 , respectively ${ }^{10-11}$.

Similar to the phase 3 trials in our study HIV RNA level remained below 100 copies $/ \mathrm{mL}$ in approximately $90 \%$ of the all treatment experienced patients at month 6 , and CD4 T-lymphocyte levels remained stable or increased depending on the level of CD4 cells.

$\mathrm{E} / \mathrm{C} / \mathrm{F} / \mathrm{TDF}$ is well tolerated; the most common adverse events reported in registration trials were diarrhea, nausea, upper respiratory infection, and headache $^{14}$. Studies by Derrick et al. valuated the safety profile of $\mathrm{E} / \mathrm{C} / \mathrm{F} / \mathrm{TDF}$ and found that the most common adverse effect were primarily gastrointestinal (9\%) followed by fatigue, headache, and skin manifestations. Overall, 20 (7\%) patients discontinued therapy: five due to fatigue, gastrointestinal complications, and dizziness, five due to virologic failure with documented integrase resistance, three due to acute kidney injury, two due to economic burden, and five for undefined reasons ${ }^{19}$.

In our study approximately $15 \%$ patients experienced adverse events. The most commonly reported adverse effects were nausea $(2.1 \%)$, diarrhea $(1.8 \%)$, pruritus $(1.6 \%)$, asthenia, headache, dizziness and dyspepsia. The discontinution rate was low $(1.6 \%)$ : two patients died due to reasons not attributed toE/C/F/TDF; four other discontinuations were reported due to drug-drug interactions, elevated creatinine, elevated liver enzyme, and physician decision.

Tenofovir alafenamide (TAF) was first approved by FDA in the form of the STR E/C/F/TAF (Genvoya $\left.{ }^{\circledR}\right)$ November $2015^{20}$. It has been a recommended regimen in the USA and European guidelines since $2015^{4,21}$. Phase 3 trials demonstrated that $\mathrm{E} / \mathrm{C} / \mathrm{F} / \mathrm{TAF}$ was superior to $\mathrm{E} / \mathrm{C} / \mathrm{F} / \mathrm{TDF}$ in terms of virologic efficacy in ART naïve and experienced patients due to lower rates of discontinuation of $\mathrm{E} / \mathrm{C} / \mathrm{F} / \mathrm{TAF}$ compared with $\mathrm{E} / \mathrm{C} / \mathrm{F} / \mathrm{TDF}^{22,23}$. However, $\mathrm{E} / \mathrm{C} / \mathrm{F} / \mathrm{TAF}$ is not available in many countries in the world; therefore, real world data on $\mathrm{E} / \mathrm{C} / \mathrm{F} / \mathrm{TDF}$ is and may also help to predict the real world effectiveness of $\mathrm{E} / \mathrm{C} / \mathrm{F} / \mathrm{TAF}$.

\section{Conclusion}

Real world data on effectiveness and safety of E/C/F/ TDF is comparable with the phase 3 trial results in both treatment-naïve and experienced patients. Adverse events are uncommon and manageable, and discontinuation rates are low. Since E/C/F/TAF and other newer regimens are not available worldwide, E/C/F/TDF may remain be recommended in the first-line regimens in treatment-naïve and experienced patients.

\section{Acknowledgement}

We would like to thank to Rukiye Zenginol, for her contributions in the data management.

This study was funded by Gilead Sciences İlaç Tic. Ltd. Şti. (Istanbul, Turkey). Gilead Sciences İlaç Ltd.Şti. was not involved to the content of the publication; no involvement to the analysis or interpretation of data/no involvement to the decision to submit for publication.

\section{References}

1. World Health Organisation. WHO | HIV data and statistics [Internet]. WHO. World Health Organization; 2017 [cited 2017 Nov 15]. Available from: http://www. who.int/hiv/data/en/

2. Turkish Public Health General Directorate. Commutable disease statistics [Internet]. 2016 [cited 2017 Nov 15]. Available from: http://www.thsk.gov.tr/ component/k2/353-istatiksel-veriler/bulasici-hastaliklar-daire-baskanligi-istatiksel-veriler.html

3. Berktas M, Unal S. Estimation of number of adults living with HIV in Turkey. Present Natl HIV/AIDS Congress 15-19 November 2017, Antalya Turkey. 2017; 4.https: / / aidsinfo.nih.gov/guidelines/html/1/ adult-and-adolescent-arv $/ 0$

5. Perry CM. Elvitegravir/Cobicistat/Emtricitabine/ 
Tenofovir Disoproxil Fumarate Single-Tablet Regimen (Stribild $\mathbb{R})$ : A Review of Its Use in the Management of HIV-1 Infection in Adults. Drugs 2014;74(1):75-97.

6. Highlights of prescribing information of Stribild [nternet] p. 3. Available from: http://www.gilead. $\mathrm{com} / \sim /$ media/Files/pdfs/medicines/hiv/stribild/ stribild_pi.pdf 7 .

7. Zolopa A, Sax PE, DeJesus E, et al. A Randomized Double-Blind Comparison of Coformulated Elvitegravir/Cobicistat/Emtricitabine/Tenofovir Disoproxil Fumarate Versus Efavirenz/Emtricitabine/Tenofovir Disoproxil Fumarate for Initial Treatment of HIV-1 Infection. J Acquir Immune Defic Syndr 2013 May 1;63(1):96-100.

8. Wohl DA, Cohen C, Gallant JE, et al. A Randomized, Double-Blind Comparison of Single-Tablet Regimen Elvitegravir/Cobicistat/Emtricitabine/Tenofovir DF Versus Single-Tablet Regimen Efavirenz/Emtricitabine/Tenofovir DF for Initial Treatment of HIV-1 Infection. J Acquir Immune Defic Syndr 2014;65(3):e118-20. 9. Clumeck N, Molina J-M, Henry K, et al. A Randomized, Double-blind Comparison of Single-Tablet Regimen Elvitegravir/Cobicistat/Emtricitabine/Tenofovir DF vs Ritonavir-Boosted Atazanavir Plus Emtricitabine/Tenofovir DF for Initial Treatment of HIV-1 Infection: analysis of week 144 results. J Acquir Immune Defic Syndr 2014;65(3):e121-4.

10. Pozniak A, Flamm J, Antinori A, et al. Switching to the single-tablet regimen of elvitegravir, cobicistat, emtricitabine, and tenofovir DF from non-nucleoside reverse transcriptase inhibitor plus coformulated emtricitabine and tenofovir DF regimens: Week 96 results of STRATEGY-NNRTI. HIV Clin Trials 2017;18(4):1418.

11. DeJesus E, Rockstroh JK, Henry K, et al. Co-formulated elvitegravir, cobicistat, emtricitabine, and tenofovir disoproxil fumarate versus ritonavir-boosted atazanavir plus co-formulated emtricitabine and tenofovir disoproxil fumarate for initial treatment of HIV-1 infection: a randomised, double-. Lancet 2012;379(9835):2429-38. 12. Cohen C, Elion R, Ruane P, et al. Randomized, phase 2 evaluation of two single-tablet regimens elvitegravir/cobicistat/emtricitabine/tenofovir disoproxil fumarate versus efavirenz/emtricitabine/tenofovir disoproxil fumarate for the initial treatment of HIV infection. AIDS 2011;25(6):F7-12.

13. Jaeckle M, Khaykin P, Haberl A, et al. Efficacy of raltegravir-containing regimens inantiretroviral-naïve and -experienced individulas in clinical practice. International Journal of STD and AIDS. 2016; 27(13):1170-9
14. Prinapori R, Di Biagio A. Efficacy, safety, and patient acceptability of elvitegravir/cobicistat/emtricitabine/tenofovir in the treatment of HIV/AIDS. Patient Prefer Adherence 2015;9:1213-8.

15. Squillace N, Ricci E, Quirino T, et al. Safety and tolerability of Elvitegravir/Cobicistat/ Emtricitabine/ Tenofovir Disoproxil fumarate in a real life setting: Data from surveillance cohort long term toxicity antiretrovirals/antivirals (SCOLTA) project. PLoS One 2017;12(6):e0179254.

16. DeJesus E, Rockstroh JK, Henry K, et al. Co-formulated elvitegravir, cobicistat, emtricitabine, and tenofovir disoproxil fumarate versus ritonavir-boosted atazanavir plus co-formulated emtricitabine and tenofovir disoproxil fumarate for initial treatment of HIV-1 infection: a randomised, double-. Lancet 2012;379(9835):2429-38. 17. Rockstroh JK, DeJesus E, Henry K, et al. A Randomized, Double-Blind Comparison of Coformulated Elvitegravir/Cobicistat/Emtricitabine/Tenofovir DF vs Ritonavir-Boosted Atazanavir Plus Coformulated Emtricitabine and Tenofovir DF for Initial Treatment of HIV-1 Infection: analysis of week 96 results. $J A c$ quir Immune Defic Syndr 2013;62(5):483-6.

18. Clumeck N, Molina J-M, Henry K, et al. A Randomized, Double-blind Comparison of Single-Tablet Regimen Elvitegravir/Cobicistat/Emtricitabine/Tenofovir DF vs Ritonavir-Boosted Atazanavir Plus Emtricitabine/Tenofovir DF for Initial Treatment of HIV-1 Infection: analysis of week 144 results. J Acquir Immune Defic Syndr 2014;65(3):e121-4.

19. Derrick CB, Lu ZK, Caulder CR, et al. Safety and Tolerability of Stribild in the Southeast United States. $J$ Assoc Provid AIDS Care 2016;15(5):432-9.

20.https://www.fda.gov/Drugs/DevelopmentApprovalProcess/DrugInnovation/ucm474696 .htm

21.http://www.eacsociety.org/files/2018_guidelines-9.1-english.pdf

22. Sax PE, Wohl D, Yin MT, et al. Tenofovir alafenamide versus tenofovir disoproxil fumarate, coformulated with elvitegravir, cobicistat, and emtricitabine, for initial treatment of HIV-1 infection: two randomised, double-blind, phase 3, non-inferiority trials. Lancet 2015;385(9987):260615.

23. Mills A, Arribas JR, Andrade-Villanueva J, et al. Switching from tenofovir disoproxil fumarate to tenofovir alafenamide in antiretroviral regimens for virologically suppressed adults with HIV-1 infection: a randomised, active-controlled, multicentre, open-label, phase 3, non-inferiority study.Lancet Infect Dis 2016;16(1):43-52. 